\title{
Accurate lattice parameter measurements of stoichiometric uranium dioxide
}

\author{
Gregory Leinders ${ }^{\mathrm{a}, \mathrm{b}, *}$, Thomas Cardinaels ${ }^{\mathrm{b}}$, Koen Binnemans ${ }^{\mathrm{a}}$, Marc \\ Verwerft ${ }^{\mathbf{b}}$
}

a KU Leuven, Department of Chemistry, Celestijnenlaan 200F, P.O. Box 2404, B-3001 Heverlee, Belgium.

b Belgian Nuclear Research Centre $(\mathrm{SCK} \bullet \mathrm{CEN})$, Institute for Nuclear Materials Science, Boeretang 200, B-2400 Mol, Belgium.

The paper presents and discusses lattice parameter analyses of pure, stoichiometric $\mathrm{UO}_{2}$. Attention was paid to prepare stoichiometric samples and to maintain stoichiometry throughout the analyses. The lattice parameter of $\mathrm{UO}_{2.000 \pm 0.001}$ was evaluated as being $547.127 \pm 0.008 \mathrm{pm}$ at $20^{\circ} \mathrm{C}$, which is substantially higher than many published values for the $\mathrm{UO}_{2}$ lattice constant and has an improved precision by about one order of magnitude. The higher value of the lattice constant is mainly attributed to the avoidance of hyperstoichiometry in the present study and to a minor extent to the use of the currently accepted $\mathrm{CuK}_{\alpha 1} \mathrm{X}$-ray wavelength value. Many of the early studies used $\mathrm{CuK}_{\alpha 1}$ wavelength values that differ from the currently accepted value, which also contributed to an underestimation of the true lattice parameter.

Keywords: uranium dioxide, $\mathrm{UO}_{2}$, lattice parameter, $\mathrm{X}$-ray diffraction

G. Leinders. T. Cardinaels, K. Binnemans, M. Verwerft, Journal of Nuclear Materials 459, 135-142 (2015).

\footnotetext{
${ }^{*}$ Corresponding author

E-mail address: gregory.leinders@sckcen.be (G. Leinders)

Phone: +321433 3163
} 


\section{Introduction}

$\mathrm{UO}_{2}$ exhibits a homogeneous range of compositions near exact stoichiometry which have an effect on the lattice parameter. For details about the uranium - oxygen system, see e.g. the reviews of McEachern and Taylor, Guéneau et al., Chevalier et al., Kurepin, Labroche et al., Baichi et al. and references therein [1-8]. Given the difficulties to keep $\mathrm{UO}_{2}$ at exact stoichiometry, precise lattice parameter determination is not straightforward. The lattice parameter has been evaluated as $547.04 \pm 0.08 \mathrm{pm}$ at $20^{\circ} \mathrm{C}$ by Grønvold in 1955 [9]. This value has been adopted as principal reference also by the International Atomic Energy Agency (IAEA) [10]. Numerous other values have been published by researchers over the past decades (Table 1). Precise knowledge of the lattice parameter of uranium dioxide $\left(\mathrm{UO}_{2}\right)$ is important for engineering and research purposes.

When exposed to air, freshly reduced $\mathrm{UO}_{2}$ powder will rapidly oxidize also at ambient temperatures. Bannister reviewed the low temperature oxidation of $\mathrm{UO}_{2}$ and found that even for powders with low specific surface area (e.g. $0.5 \mathrm{~m}^{2} \mathrm{~g}^{-1}$ ), O/U ratios of 2.006 can be found after $24 \mathrm{~h}$ of exposure [11]. For powders with a higher specific surface, the limiting amount of hyperstoichiometry can be much higher. The oxidation mechanism is chemisorption of oxygen which starts already at the boiling isotherm of oxygen, i.e. at $-183{ }^{\circ} \mathrm{C}$, followed by sub-surface oxidation which starts around $-130{ }^{\circ} \mathrm{C}[12,13]$. The sub-surface oxidation is limited to a depth of approximately $5 \mathrm{~nm}$ and it is invariant for temperatures up to $50^{\circ} \mathrm{C}$, the amount of oxygen absorbed being proportional to the surface area [13]. The oxidation of sintered polycrystalline $\mathrm{UO}_{2}$ follows the same mechanisms and for pellets with high levels of open porosity, macroscopically measurable oxidation can be observed. For pellets which are sintered to densities above $95 \%$ of the theoretical density (T.D.), i.e. when all porosity is closed, the oxidation at ambient conditions is limited to the formation of a thin surface layer. Bulk oxidation is measured only at higher temperatures $\left(>100{ }^{\circ} \mathrm{C}\right.$ ), where oxygen diffusion proceeds at a detectable rate $[1,14]$.

Upon oxidation the cubic lattice of $\mathrm{UO}_{2}$ (Figure 1) slightly distorts and contracts. Oxygen atoms are incorporated in the cubic-coordinated interstitial sites which are displaced in either the $\langle 110\rangle$ or the $\langle 111\rangle$ direction and oxygen vacancies are formed at the normal sites, with the uranium sublattice remaining undisturbed [15-17]. Willis concluded that the defects cluster together in defect clusters or complexes, with each complex containing interstitial oxygen atoms and vacant normal oxygen sites in the so-called 2:2:2 configuration [18]. The $\mathrm{UO}_{2}$ lattice contraction is attributed to charge compensation: the excess oxygen is balanced by a valence shift of $U^{4+}$ to $U^{5+/ 6+}$. The ionic radii of $U^{5+/ 6+}$ being smaller than that of $U^{4+}$ and the higher specific charge result in a net lattice contraction. This effect is quite substantial and various contraction ratios have been reported, ranging from $-5.5 \times 10^{-3} \mathrm{pm}$ to $-15 \times 10^{-3} \mathrm{pm}$ per 0.001 amount of hyperstoichiometry [19-25]. 


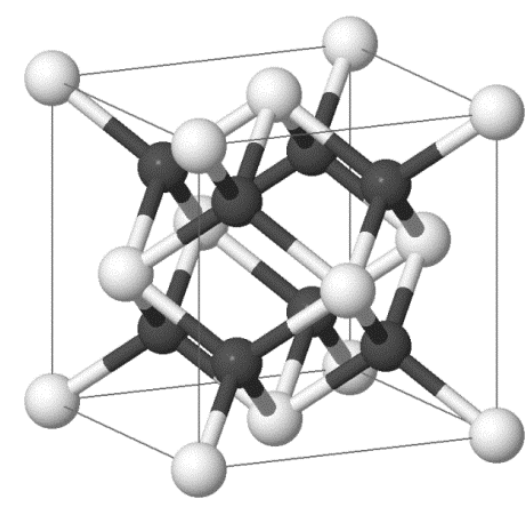

Figure 1. Unit cell of the face-centered cubic crystal structure of $\mathrm{UO}_{2}$. The tetrahedralcoordinated anion sites (oxygen sublattice) are shown in black. The cubic-coordinated cation sites (uranium sublattice) are shown in light grey shade. The normal interstitial sites are found in the cell edge centers $(0,0,1 / 2),(0,1 / 2,0),(1 / 2,0,0)$ and the cell center $(1 / 2,1 / 2,1 / 2)$. Illustration created with Jmol [26].

Recent work by some of us reported a lattice parameter of $\mathrm{UO}_{2.001}$ which was higher than the generally accepted value [27,28]. The focus of that work was on lattice contraction with doping and not specifically oriented on the pure $\mathrm{UO}_{2}$ material. In the present work, we focus on undoped $\mathrm{UO}_{2}$ and we pay specific attention to avoid deviations from stoichiometry.

For the experimental assessment of the lattice parameter of stoichiometric $\mathrm{UO}_{2}$, we have prepared densely sintered polycrystalline pellets (T.D. > 97\%) under two different reducing atmospheres and for one of the conditions, we used two different feed powders. Precise X-ray diffraction and thermogravimetric measurements were performed and yielded a consistent set of data from which an accurate value of the lattice parameter of $\mathrm{UO}_{2.000}$ is derived. The parameters influencing the accuracy of the lattice parameter are carefully analyzed and evaluated. 
Table 1. Selection ${ }^{\mathrm{a}}$ of the published data on the lattice parameter of $\mathrm{UO}_{2}$.

\begin{tabular}{|c|c|c|c|c|}
\hline $\begin{array}{l}\text { Lattice parameter } \\
a(\mathrm{pm}) \text { reported }\end{array}$ & $\begin{array}{l}\text { Temperature } \\
\text { reported }\left({ }^{\circ} \mathrm{C}\right)\end{array}$ & $\begin{array}{l}\text { Lattice parameter } \\
a(\mathrm{pm}) \text { at } 20^{\circ} \mathrm{C}^{\mathbf{b}}\end{array}$ & $\begin{array}{l}\mathrm{O} / \mathrm{U} \text { ratio } \\
\text { stated }\end{array}$ & Reference \\
\hline $547.109 \pm 0.006$ & $25.3 \pm 0.5$ & 547.081 & 2.001 & $\begin{array}{l}\text { Cardinaels, } \\
2012 \text { [27] }\end{array}$ \\
\hline $547.0^{\mathrm{c}}$ & 20 & 547.0 & $2^{\mathrm{d}}$ & $\begin{array}{l}\text { Hutchings, } \\
1987 \text { [29] }\end{array}$ \\
\hline $546.96 \pm 0.04^{\mathrm{e}}$ & & & $2^{\mathrm{e}}$ & $\begin{array}{l}\text { Alekseyev, } \\
1981 \text { [24] }\end{array}$ \\
\hline $547.06 \pm 0.05$ & 25 & 547.03 & 2.001 & $\begin{array}{l}\text { Lynds, } \\
1963 \text { [20] }\end{array}$ \\
\hline $546.9 \pm 0.1$ & & & $2.00^{\mathrm{d}}$ & Blackburn, \\
\hline $547.1 \pm 0.1$ & & & 2.00 & $1958[14]$ \\
\hline $547.04 \pm 0.08$ & $20 \pm 2$ & 547.04 & 2.00 & $\begin{array}{l}\text { Grønvold, } \\
1955 \text { [9] }\end{array}$ \\
\hline $546.91 \pm 0.01^{\mathrm{f}}$ & & & 2.000 & $\begin{array}{l}\text { Perio, } \\
1953 \text { [19] }\end{array}$ \\
\hline $546.8 \pm 0.1^{\mathrm{f}}$ & & & 2.00 & $\begin{array}{l}\text { Herring, } \\
1952[30]\end{array}$ \\
\hline
\end{tabular}

${ }^{\text {a }}$ Values were selected from researchers that sufficiently specified their sample preparation methods, analysis methods and uncertainties.

${ }^{\mathrm{b}}$ Lattice parameter values reported at a specific temperature are recalculated to $20{ }^{\circ} \mathrm{C}$ using the thermal linear expansion coefficient of $\mathrm{UO}_{2}$ [31].

${ }^{c}$ Measured with neutron diffraction on a single crystal sample.

${ }^{\mathrm{d}}$ Assumed value.

${ }^{\mathrm{e}}$ Extrapolated result to $\mathrm{O} / \mathrm{U}=2$.

${ }^{\mathrm{f}}$ Original value converted from $k X$ unit by multiplying a factor $100.2077 \mathrm{pm}$ [32]. 


\section{Experimental}

\subsection{Sample preparation}

Three samples were prepared from two batches of depleted uranium oxide powder $\left(\sim \mathrm{UO}_{2.1}\right)$ obtained via Integrated Dry Route (IDR) synthesis and supplied by FBFC International (Dessel, Belgium). The two batches differed in impurity content, both being of nuclear grade. Chemical analysis of the starting material is shown in paragraph 3.1.

The samples were prepared using an identical approach. The as-received powder was compacted at $400 \mathrm{MPa}$ into cylindrical pellets. A semi-automatic press (Specac Atlas 8T) was used with a compaction time of $30 \mathrm{~s}$. The pressing die and punches were lubricated with a saturated solution of stearic acid in acetone. This ensured a safe operation of the press and the production of high quality green pellets. Several $\mathrm{UO}_{2}$ pellets were prepared for each experimental route.

Sintering was performed to reduce the $\mathrm{UO}_{2.1}$ to stoichiometry and to densify the green bodies to almost complete density. A Linn HT 1800 Moly high-temperature furnace with an alumina matrix and molybdenum heating elements was used. The sintering atmosphere was monitored with a dew point analyzer and an oxygen analyzer. The dew point of the exiting gas is $-80^{\circ} \mathrm{C}$, owing to a very good gas tightness of the system. Green pellets were placed in an alumina crucible fitted with a molybdenum sheet. After placing the crucible containing the samples in the furnace, the system was sealed and flushed until the dew point of the exiting gas reached $-60{ }^{\circ} \mathrm{C}$ or less.

Table 2. Parameters changed between the three samples.

\begin{tabular}{lcc}
\hline Sample & $\begin{array}{c}\text { Powder } \\
\text { batch }\end{array}$ & $\begin{array}{c}\boldsymbol{\mu} \text { o2 at sintering } \\
\text { temp. }\left(\mathbf{k J ~ m o l}^{-1}\right)\end{array}$ \\
\hline UO2 (A) & 1 & $-420 \pm 10$ \\
UO2 (B) & 1 & $-540 \pm 10$ \\
$\mathbf{U O}_{2}$ (C) & 2 & $-540 \pm 10$ \\
\hline
\end{tabular}

Two different sintering conditions were used (Table 2). A heating rate of $5{ }^{\circ} \mathrm{C} \mathrm{min}^{-1}$ was always applied. The sintering temperature was $1680^{\circ} \mathrm{C}$ and maintained for $4 \mathrm{~h}$. The cooling rate was inherent to the furnace and decreased logarithmic from $5{ }^{\circ} \mathrm{C} \mathrm{min}{ }^{-1}$ to about $0.5{ }^{\circ} \mathrm{C}$ $\min ^{-1}$ during $15 \mathrm{~h}$. Sample A was sintered under a mixture of 5 vol.\% hydrogen and 0.5 vol.\% oxygen in argon. Sample B and C were sintered under a gas atmosphere containing 5 vol.\% hydrogen in argon. Final density was $>97 \%$, and the remaining porosity was fully closed. 


\subsection{Thermogravimetric analysis}

The stoichiometry was measured by thermogravimetric analysis (TGA) with a Netzsch STA 449 F1 Jupiter ${ }^{\circledR}$. Compounds in the exiting gas flow could be identified with an in-line $403 \mathrm{D}$ Aëolos ${ }^{\circledR}$ quadrupole mass spectrometer. The oxygen and water contents of the exiting gas were monitored with an oxygen and dew point analyzer, respectively. The ASTM C1453-00 standard procedure for measuring the uranium and oxygen-to-uranium atomic ratio by the ignition impurity correction method was used as a basis for the practical procedure using TGA.

Fragments of a sintered pellet (approximately $1 \mathrm{~g}$ in total) were placed in an alumina crucible and weighed on an analytical balance in lab environment. After insertion in the TGA apparatus the furnace was sealed, evacuated and refilled with dry argon gas three consecutive times to remove atmospheric impurities. During analysis a constant flow of synthetic air was maintained in the furnace chamber. The sample was heated to $500{ }^{\circ} \mathrm{C}$ and remained at this temperature for $3.5 \mathrm{~h}$. This ensured complete oxidation to $\mathrm{U}_{3} \mathrm{O}_{8}$ of the initial material. Preliminary tests showed that a preheating step to correct for mass loss due to desorption was not required on these samples.

In the used configuration, the absolute uncertainty on weight readout was measured to be \pm 14 $\mu \mathrm{g}(1 \sigma)$, taking drift and noise of the apparatus into account.

\subsection{X-ray diffraction}

Accurate lattice parameter measurements were done by X-ray diffraction. A Philips X'Pert Pro diffractometer utilizing the Bragg-Brentano parafocusing geometry and a $\theta-\theta$ configuration was employed. Zero point calibration was performed with a sintered Si disc of high purity. Validation is performed against a sintered $\mathrm{Al}_{2} \mathrm{O}_{3}$ disc (NIST Standard Reference Material 1976b) on a weekly basis. The instrument bias was assessed by verifying the lattice parameter refinement of $\mathrm{Si}$ and found to be smaller than $10^{-5}$ relative $(1 \sigma)$.

An LFF X-ray tube $\left(\mathrm{CuK}_{\alpha 1}=1.5405929 \AA\right.$ [33]) was used as radiation source. The optics of the incident and diffracted beam path were carefully aligned and optimized for the specific samples to ensure a maximum in recorded peak intensity while keeping the scatter from the sample holder as low as possible. A fixed divergence slit in combination with 0.02 rad Soller slits and a copper beam mask ensured the measurement of high-quality diffractograms with low axial divergence. The diffracted beam path was foreseen with $0.02 \mathrm{rad}$ Soller slits and a Ni filter. Detection was done with a position-sensitive detector (PANalytical X'Celerator). This detector operated in scanning mode with an active length of $2.122^{\circ}(2 \theta)$. All 
diffractograms were recorded with a continuous scan in the range $27-141^{\circ}(2 \theta)$, using a step size of $0.004^{\circ}$. The total measuring time was $120 \mathrm{~min}$.

The lattice parameter was calculated using the unit cell refinement method in the PANalytical X'Pert HighScore Plus software. Only $\mathrm{K}_{\alpha 1}$ reflections were used in the calculation. This least squares method takes all recorded reflections into account. The uncertainty $(1 \sigma)$ on the lattice parameter is combined with the effect of sample temperature uncertainty (see §3.3). Sample displacements were measured and corrected for via the software. Lattice parameters were recalculated to their values at a reference state of $20^{\circ} \mathrm{C}$. For this purpose, the linear thermal expansion coefficient for $\mathrm{UO}_{2}\left(9.739 \times 10^{-6}{ }^{\circ} \mathrm{C}^{-1}\right.$ near room temperature $)$ was used [31].

Sintered pellets were embedded in a conducting phenolic resin by hot mounting in a Struers CitoPress. The side showing the inserted pellet was then grinded with SiC sanding paper of successively smaller grain sizes (smallest grain size: $3 \mu \mathrm{m}$ ) and finished by polishing on cloths with diamond paste (grain size: $1 \mu \mathrm{m}$ ) to achieve a flat and mirror-like surface.

\subsection{Impurity analysis}

A quantitative evaluation of the trace elements in the starting powder was made via inductively coupled plasma-mass spectrometry (ICPMS) using a ThermoFisher XSeries2. In particular, elements such as lead, the lanthanides and some of the actinides were focused on. In total, 50 elements were measured. A sample of the oxide powder $(1 \mathrm{~g})$ was dissolved in 8 $\mathrm{M}$ nitric acid solution. Aliquots of this solution were further diluted and prepared for analysis.

The instrument was used in the manufacturer's standard configuration. The elements were divided into convenient to measure groups based on their atomic masses, their expected concentrations and potential interferences. Multi-element calibration standards containing the elements in each of these groups were prepared from single-element standards (except for $\mathrm{Np}$ and $\mathrm{Pu}$ ). Internal standards (Sc, Y, Rh, La, Lu, Ir, Th) were used to correct for any internal drift. Quantification was done by external calibration, except for $\mathrm{Np}$ and $\mathrm{Pu}$. The instrumental response is almost constant at high masses, so the response at $m / z=235$ for a known concentration of a depleted $\left(0.56\right.$ at. $\left.\%{ }^{235} \mathrm{U}\right)$ single element $\mathrm{U}$ standard can be applied to other actinides and used to quantify the mass fractions of the ${ }^{237} \mathrm{~Np}$ and ${ }^{240} \mathrm{Pu}$ and ${ }^{242} \mathrm{Pu}$ isotopes.

The isotope ratios were determined by TIMS (Thermal Ionization Mass Spectrometry) using a VG Sector 54 instrument. The instrument is equipped with 5 Faraday cups and isotope amount ratio measurements were performed in static mode monitoring masses at $\mathrm{m} / \mathrm{z}=233$, 234, 235, 236, 238 using non-zone refined rhenium triple filaments which were loaded with approximately $1 \mu \mathrm{g}$ of uranium. The samples were evaporated conventionally, once measurements of quality control standards at the start of the analysis sequence were within 
specification. Mass fractionation was corrected for by using external standard reference materials certified for their ${ }^{235} \mathrm{U} /{ }^{238} \mathrm{U}$ isotope ratios. 


\section{Results}

\subsection{Chemical analysis}

The amount of impurities was as expected for depleted uranium oxide obtained via IDR synthesis (see Table 3). The total amount of quantifiable metallic impurities was equal to $93 \pm 41 \mu \mathrm{g} \mathrm{g}^{-1}$ for batch 1 , and $37 \pm 21 \mu \mathrm{g} \mathrm{g}^{-1}$ for batch 2 . The remainder of the selected impurity elements were present in quantities below their limit of detection. From the results of TIMS analysis the atomic weight of $\mathrm{U}$ is found to be $238.04252 \pm 0.00002 \mathrm{~g} \mathrm{~mol}^{-1}$ in batch 1 . In batch 2 , this value was equal to $238.04104 \pm 0.00002 \mathrm{~g} \mathrm{~mol}^{-1}$.

Table 3. Quantifiable impurity levels measured via ICPMS in uranium oxide powder batch 1 and $2^{\mathrm{a}}$. Values given in $\mu \mathrm{g} \mathrm{g}^{-1}$.

\begin{tabular}{lrr|lrr}
\hline & Batch 1 & \multicolumn{1}{c}{ Batch 2 } & Batch 1 & Batch 2 \\
\hline $\mathbf{L i}$ & $1.0 \pm 0.7$ & $0.9 \pm 0.7$ & $\mathbf{Z n}$ & $8 \pm 4$ & $1.5 \pm 0.8$ \\
$\mathbf{B e}$ & $<0.06$ & $0.09 \pm 0.06$ & $\mathbf{Z r}$ & $0.09 \pm 0.05$ & $0.06 \pm 0.04$ \\
$\mathbf{B}$ & $2.9 \pm 1.5$ & $1.8 \pm 1.3$ & $\mathbf{M o}$ & $0.36 \pm 0.21$ & $0.18 \pm 0.14$ \\
$\mathbf{M g}$ & $14 \pm 7$ & $<2$ & $\mathbf{C d}$ & $0.06 \pm 0.04$ & $0.08 \pm 0.05$ \\
$\mathbf{A l}$ & $26 \pm 8$ & $4.1 \pm 1.4$ & $\mathbf{I n}$ & $0.026 \pm 0.014$ & $0.018 \pm 0.010$ \\
$\mathbf{C r}$ & $1.2 \pm 0.6$ & $0.27 \pm 0.17$ & $\mathbf{S n}$ & $5 \pm 5$ & $4 \pm 4$ \\
$\mathbf{M n}$ & $0.44 \pm 0.22$ & $0.28 \pm 0.14$ & $\mathbf{B a}$ & $0.58 \pm 0.23$ & $<0.5$ \\
$\mathbf{F e}$ & $15 \pm 8$ & $23 \pm 12$ & $\mathbf{L a}$ & $0.034 \pm 0.010$ & $0.025 \pm 0.008$ \\
$\mathbf{C o}$ & $0.035 \pm 0.021$ & $<0.01$ & $\mathbf{C e}$ & $0.007 \pm 0.003$ & $<0.001$ \\
$\mathbf{N i}$ & $15 \pm 4$ & $0.53 \pm 0.16$ & $\mathbf{G d}$ & $0.033 \pm 0.017$ & $0.006 \pm 0.004$ \\
$\mathbf{C u}$ & $2.9 \pm 1.5$ & $0.15 \pm 0.11$ & $\mathbf{P b}$ & $0.40 \pm 0.20$ & $0.11 \pm 0.05$ \\
\hline
\end{tabular}

${ }^{a}$ The remainder of the selected impurity elements were $\mathrm{Na}, \mathrm{Si}, \mathrm{P}, \mathrm{K}, \mathrm{Ca}, \mathrm{Ti}, \mathrm{V}, \mathrm{Rb}, \mathrm{Sr}, \mathrm{Ag}$, $\mathrm{Nd}, \mathrm{Sm}, \mathrm{Eu}, \mathrm{Tb}, \mathrm{Dy}, \mathrm{Ho}, \mathrm{Er}, \mathrm{Tm}, \mathrm{Yb}, \mathrm{Lu}, \mathrm{Ta}, \mathrm{W}, \mathrm{Hg}, \mathrm{Bi}, \mathrm{Th},{ }^{237} \mathrm{~Np},{ }^{240} \mathrm{Pu},{ }^{242} \mathrm{Pu}$.

The stoichiometry analysis (see next paragraph) is substantially affected by the presence of impurities. Not only is the calculated metallic fraction of $U$ affected, some species may also react during oxidation thus contributing to the witnessed mass difference. Table 4 lists the expected molecular form of the quantifiable impurities present in the sintered and oxidized sample. Using these data, the maximum weight contribution of the quantifiable impurities is recalculated. Samples A and B contain an estimated $136 \pm 59 \mu \mathrm{g} \mathrm{g}^{-1}$ of impurity compounds after sintering. After oxidation this value increases to $149 \pm 65 \mu \mathrm{g} \mathrm{g}^{-1}$. Sample C contains an estimated $47 \pm 27 \mu \mathrm{g} \mathrm{g}^{-1}$ of impurity compounds after sintering. After oxidation this value increases to $62 \pm 33 \mu \mathrm{g} \mathrm{g}^{-1}$. The stoichiometry analysis is corrected for these effects.

Some impurities are expected to evaporate. In the case of total evaporation of all the compounds indicated in Table 4, we calculated the resulting effect on the measured stoichiometry to be $<0.0001$. 
Table 4. Molecular form of selected impurities in the initial and oxidized sample.

\begin{tabular}{|c|c|c|}
\hline \multirow[b]{2}{*}{$\begin{array}{l}\text { Impurity } \\
\text { element }\end{array}$} & \multicolumn{2}{|c|}{ Molecular form in } \\
\hline & $\begin{array}{l}\text { Initial sample } \\
\text { (sintered) }\end{array}$ & $\begin{array}{l}\text { Oxidized } \\
\text { sample }\end{array}$ \\
\hline $\mathbf{L i}$ & $\mathrm{Li}_{2} \mathrm{O}$ & $\mathrm{Li}_{2} \mathrm{O}$ \\
\hline Be & $\mathrm{BeO}$ & $\mathrm{BeO}$ \\
\hline $\mathbf{B}$ & $\mathrm{B}_{2} \mathrm{O}_{3}{ }^{\mathrm{a}}$ & $\mathrm{B}_{2} \mathrm{O}_{3}$ \\
\hline Mg & $\mathrm{MgO}$ & $\mathrm{MgO}$ \\
\hline Al & $\mathrm{Al}_{2} \mathrm{O}_{3}$ & $\mathrm{Al}_{2} \mathrm{O}_{3}$ \\
\hline $\mathrm{Cr}$ & $\mathrm{Cr}_{2} \mathrm{O}_{3}{ }^{\mathrm{a}}$ & $\mathrm{Cr}_{2} \mathrm{O}_{3}$ \\
\hline Mn & $\mathrm{MnO}^{\mathrm{a}}$ & $\mathrm{MnO}_{2}$ \\
\hline $\mathbf{F e}$ & $\mathrm{Fe}$ & $\mathrm{Fe}_{2} \mathrm{O}_{3}$ \\
\hline Co & $\mathrm{Co}$ & $\mathrm{CoO}$ \\
\hline $\mathbf{N i}$ & $\mathrm{Ni}$ & $\mathrm{NiO}$ \\
\hline $\mathbf{C u}$ & $\mathrm{Cu}$ & $\mathrm{CuO}$ \\
\hline Zn & $\mathrm{ZnO}^{\mathrm{a}}$ & $\mathrm{ZnO}$ \\
\hline $\mathbf{Z r}$ & $\mathrm{ZrO}_{2}$ & $\mathrm{ZrO}_{2}$ \\
\hline Mo & Mo & $\mathrm{MoO}_{3}{ }^{\mathrm{a}}$ \\
\hline Cd & $\mathrm{Cd}^{\mathrm{a}}$ & $\mathrm{CdO}$ \\
\hline In & $\mathrm{In}^{\mathrm{a}}$ & $\mathrm{In}_{2} \mathrm{O}_{3}$ \\
\hline Sn & $\mathrm{Sn}^{\mathrm{a}}$ & $\mathrm{SnO}_{2}$ \\
\hline $\mathbf{B a}$ & $\mathrm{BaO}$ & $\mathrm{BaO}$ \\
\hline $\mathbf{L a}$ & $\mathrm{La}_{2} \mathrm{O}_{3}$ & $\mathrm{La}_{2} \mathrm{O}_{3}$ \\
\hline $\mathrm{Ce}$ & $\mathrm{Ce}_{2} \mathrm{O}_{3}$ & $\mathrm{CeO}_{2}$ \\
\hline Gd & $\mathrm{Gd}_{2} \mathrm{O}_{3}$ & $\mathrm{Gd}_{2} \mathrm{O}_{3}$ \\
\hline $\mathbf{P b}$ & $\mathrm{Pb}^{\mathrm{a}}$ & $\mathrm{PbO}_{2}$ \\
\hline
\end{tabular}

${ }^{\mathrm{a}}$ Will evaporate during heat treatment.

\subsection{Stoichiometry measurement}

A general way for determining the unknown stoichiometry $x$ in a $\mathrm{UO}_{2+x}$ sample is the method based on the weight difference after oxidation to $\mathrm{U}_{3} \mathrm{O}_{8}$ (cf. ASTM C1453-00). Here, the atomic fraction of uranium is calculated from the amount of $\mathrm{U}_{3} \mathrm{O}_{8}$ obtained. Ideally, only the reaction

$$
3 \mathrm{UO}_{2+x}+\frac{1}{2}(2-3 x) \mathrm{O}_{2} \rightarrow \mathrm{U}_{3} \mathrm{O}_{8}
$$

accounts for the weight gain after oxidation, resulting in a straight-forward calculation to obtain the initial stoichiometry. In practice, however, the presence of impurities must be corrected for. Also, if adsorbates are present on either the initial sample with unknown stoichiometry, on $\mathrm{U}_{3} \mathrm{O}_{8}$, or on both, the recorded weight change differs from the ideal case.

The fraction of uranium per initial sample weight $\left(\mathrm{U}_{w}\right)$ was calculated using Eq. (2) 


$$
\mathrm{U}_{w}=\left(\frac{1}{y} \cdot \frac{z \cdot\left(1-I_{O}\right)}{1+\frac{8 \cdot M_{\mathrm{O}}}{3 \cdot M_{\mathrm{U}}}}\right)-C_{n q}
$$

with $y$ the initial sample weight of $\mathrm{UO}_{2+x}(\mathrm{~g}), z$ the resulting $\mathrm{U}_{3} \mathrm{O}_{8}$ sample weight $(\mathrm{g}), I_{O}$ the total amount of all impurity compounds present per gram $\mathrm{U}_{3} \mathrm{O}_{8}\left(\mathrm{~g} \mathrm{~g}^{-1}\right)$, and $M_{\mathrm{O}}(=15.99940 \mathrm{~g}$ $\mathrm{mol}^{-1}$ ) and $M_{\mathrm{U}}$ the atomic weights of oxygen and uranium, respectively. The value of the atomic weight of uranium is the one calculated from its actual isotopic vector as shown in $\S 3.1$. Additionally, the $\mathrm{U}_{w}$ value is lowered with a constant value $\left(C_{n q}=0.0001 \mathrm{~g} \mathrm{~g}^{-1}\right.$, or 100 $\mu \mathrm{g} \mathrm{g}^{-1}$ ) to correct for the presence of non-quantifiable impurities (ASTM C1453-00). Finally, the stoichiometry $(\mathrm{O} / \mathrm{U})$ is calculated using Eq. (3)

$$
\mathrm{O} / \mathrm{U}=\frac{M_{\mathrm{U}}}{M_{\mathrm{O}}} \cdot \frac{1-\mathrm{U}_{w}-I}{\mathrm{U}_{w}}
$$

with $I$ the total amount of impurity elements and compounds present per initial sample weight $\left(\mathrm{g} \mathrm{g}^{-1}\right)$. Correction for moisture content was left out as our TGA tests showed no detectable mass loss from sintered pellet fragments heated at $150{ }^{\circ} \mathrm{C}$ in inert atmosphere for $3 \mathrm{~h}$.

The stoichiometry of the pellets was derived from the in situ mass difference at $50{ }^{\circ} \mathrm{C}$, i.e. before and after oxidation. An overview of the results is given in Table 5. All three samples can be considered to be stoichiometric, within the error of the measurement.

Table 5. Stoichiometry of the different samples.

\begin{tabular}{lll}
\hline Sample & O/U & $\begin{array}{l}\text { Propagated } \\
\text { error }\end{array}$ \\
\hline $\mathbf{U O}_{2}$ (A) & 1.999 & \pm 0.001 \\
$\mathbf{U O}_{2}$ (B) & 2.000 & \pm 0.001 \\
$\mathbf{U O}_{2}$ (C) & 1.9997 & \pm 0.0006 \\
\hline
\end{tabular}

The following experimental uncertainties were taken into account for the propagated error on the stoichiometry: quantifiable and non-quantifiable impurities, weight readout, atomic weight, and isotopic vector of uranium. Using the values as shown in Table 6 the propagated error on the calculated stoichiometry of samples A and B is equal to $\pm 0.001(1 \sigma)$ while that of sample $\mathrm{C}$ is equal to $\pm 0.0006(1 \sigma)$. 
Table 6. Overview of the various experimental uncertainties and their effect on stoichiometry measurement by TGA.

\begin{tabular}{|c|c|c|c|}
\hline \multirow{3}{*}{$\begin{array}{l}\text { Quantifiable impurities } \\
\left(\mu \mathrm{g} \mathrm{g}^{-1}\right)\end{array}$} & & Uncertainty & Effect on stoichiometry \\
\hline & Batch 1 & $\begin{array}{ll}\text { Sintered: } & 59 \\
\text { Oxidized: } & 65\end{array}$ & \pm 0.001 \\
\hline & Batch 2 & $\begin{array}{ll}\text { Sintered: } & 27 \\
\text { Oxidized: } & 33\end{array}$ & \pm 0.0005 \\
\hline \multicolumn{2}{|c|}{ Analytical balance uncertainty $(\mu \mathrm{g})$} & 20 & \pm 0.0003 \\
\hline \multicolumn{2}{|c|}{ STA balance uncertainty $(\mu \mathrm{g})$} & 14 & \pm 0.0002 \\
\hline \multicolumn{2}{|c|}{ Non-quantifiable impurities $\left(\mu \mathrm{g} \mathrm{g}^{-1}\right)$} & 10 & \pm 0.0002 \\
\hline \multicolumn{2}{|c|}{ Oxygen atomic weight $\left(\mu \mathrm{g} \mathrm{mol}^{-1}\right)$} & 10 & \pm 0.0001 \\
\hline \multicolumn{2}{|c|}{ Uranium atomic weight $\left(\mu \mathrm{g} \mathrm{mol}^{-1}\right)$} & 20 & \pm 0.000008 \\
\hline
\end{tabular}

\subsection{X-ray diffraction}

The measured lattice parameter values $\left(a_{T}\right)$ are shown in Table 7. Each sample was measured two times over the course of two weeks. The uncertainty on the as-measured lattice parameter $\left(\sigma_{\mathrm{a}_{\mathrm{T}}}\right)$ is obtained from the least squares refinement.

Table 7. Lattice parameter results of the different samples.

\begin{tabular}{|c|c|c|c|c|c|c|c|}
\hline Sample & $\begin{array}{c}\text { Lattice } \\
\text { parameter } \\
a_{T}(\mathrm{pm})\end{array}$ & $\begin{array}{c}\sigma_{a_{T}} \\
(\mathbf{p m})\end{array}$ & $\begin{array}{c}\text { Temperature } \\
\text { ante-post } \\
\left({ }^{\circ} \mathbf{C}\right)\end{array}$ & $\begin{array}{c}\Delta a \\
(\mathbf{p m})\end{array}$ & $\begin{array}{c}\sigma_{\Delta a} \\
(\mathbf{p m})\end{array}$ & $\begin{array}{c}\text { Lattice } \\
\text { parameter } a \\
\text { at } 20^{\circ} \mathrm{C}(\mathbf{p m})\end{array}$ & $\begin{array}{c}\sigma_{a} \\
(\mathbf{p m})\end{array}$ \\
\hline \multirow[t]{2}{*}{$\mathrm{UO}_{2}(\mathrm{~A})$} & 547.159 & 0.002 & $24.5-26.0$ & -0.028 & 0.002 & 547.131 & 0.003 \\
\hline & 547 & 0 & 2 & -( & 0.002 & 54 & 0.003 \\
\hline \multirow[t]{2}{*}{$\mathrm{UO}_{2}(\mathrm{~B})$} & 547.162 & 0.002 & $25.5-27.0$ & -0.033 & 0.002 & 547 & 0.003 \\
\hline & 547.157 & 0.002 & $24.5-26.0$ & -0.028 & 0.002 & 547.129 & 0.003 \\
\hline \multirow[t]{2}{*}{$\mathrm{UO}_{2}(\mathrm{C})$} & 547.149 & 0.003 & $25.0-26.5$ & -0.030 & 0.002 & 547.119 & 0.004 \\
\hline & 547.158 & 0.003 & $25.0-26.5$ & -0.031 & 0.002 & 547.127 & 0.004 \\
\hline
\end{tabular}

${ }^{\text {a }}$ Temperature inside the XRD apparatus after thermal stabilization, directly before and after XRD analysis.

Samples were thermally stabilized in the XRD apparatus overnight. The temperature inside the apparatus was measured directly before and after X-ray analysis. The average of these two values $(T)$ was used to correct for thermal expansion of the lattice $(\Delta a)$. The as-measured lattice parameter $a_{T}$ at temperature $T$ is recalculated to its value at $20{ }^{\circ} \mathrm{C}$ according to the equation

$$
a=a_{T}(1-\alpha(T-20))
$$

with $\alpha=9.739 \times 10^{-6}{ }^{\circ} \mathrm{C}^{-1}$ the linear thermal expansion coefficient for $\mathrm{UO}_{2}$ [31]. The probability distribution of the temperature is conservatively taken as uniform, with central value the average of the two readings $\left(T_{2}, T_{1}\right)$ and width $\Delta T=T_{2}-T_{1}$. The variance is then 
$\frac{1}{3}\left(\frac{\Delta T}{2}\right)^{2}$ and the uncertainty $\frac{\Delta T}{2 \sqrt{3}}$. The uncertainty on temperature correction $\left(\sigma_{\Delta a}\right)$ is calculated using Eq. (4). Combination of these uncertainties yields the propagated error on the corrected lattice parameter $\left(\sigma_{a}\right)$

The parameters used in this study to assess the quality of the measured X-ray diffractograms are: (1) the net statistical counting error, calculated through the Jenkins and Schreiner figure of merit (FOM) [34], (2) the full width at half-maximum (FWHM) of the (422) peak, measured as $2 \theta\left(^{\circ}\right)$, and (3) the scatter on the observed peak positions relative to the theoretical peak positions. This last parameter, which describes the quality of the metric aspects of the powder pattern, is also estimated by the Smith and Snyder FOM [35]. Table 8 shows the average results of the quality assessment of the diffractograms used for calculating the lattice parameter of the $\mathrm{UO}_{2}$ samples. The narrow scatter on the peak positions is recognized in the very high Smith and Snyder FOM values, which indicate excellent quality of the recorded diffractograms [36]. Figure 2 shows the recorded XRD pattern of sample B together with the residual on the peak positions. All measured patterns were consistent throughout the analysis period.

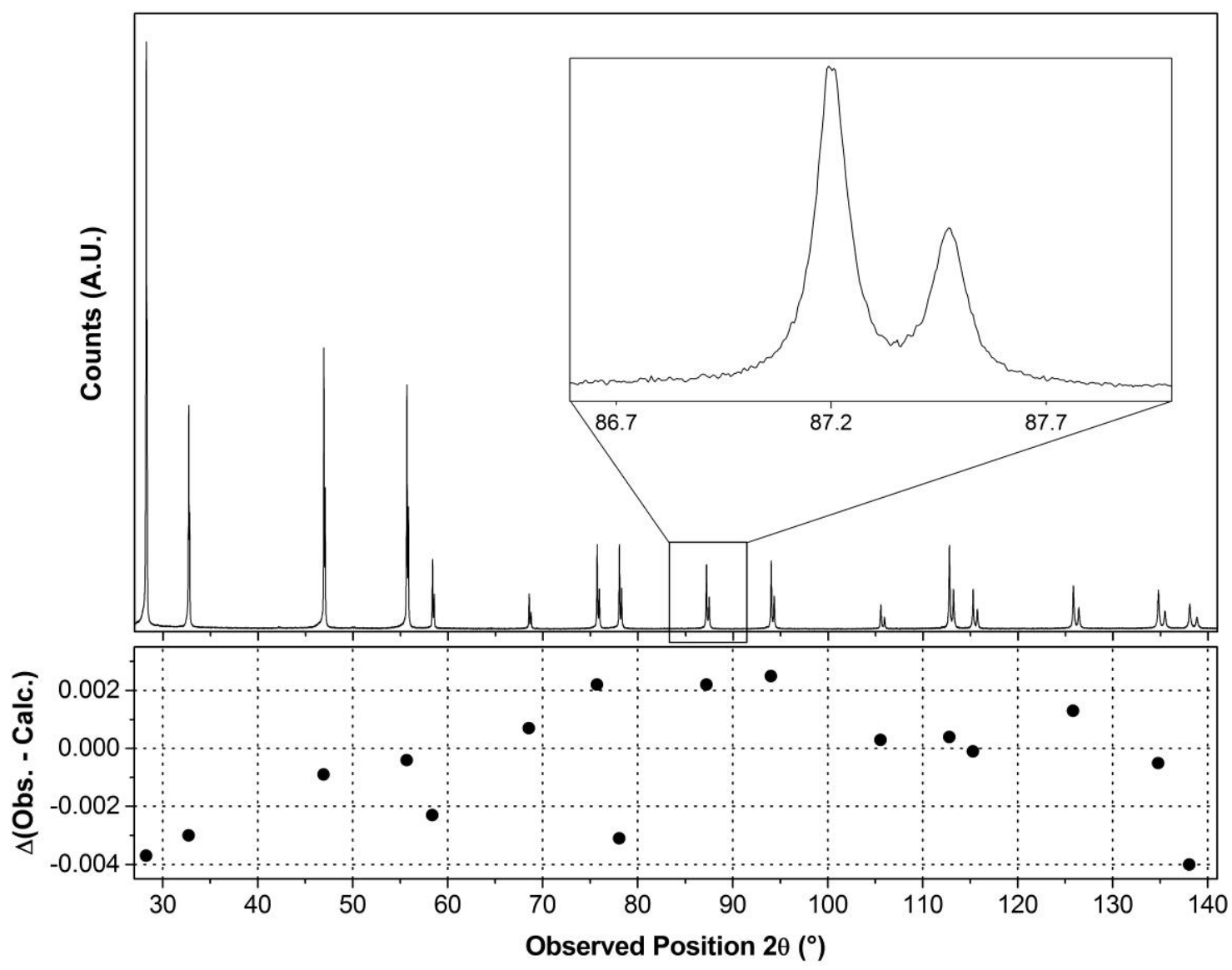

Figure 2. XRD pattern of sample B. The inset shows a close up of the $\mathrm{UO}_{2}(422)$ reflection. At the bottom, the observed peak scatter is plotted. 
Table 8. Assessment of the quality aspects of the recorded X-ray diffractograms.

\begin{tabular}{|c|c|c|c|c|}
\hline Sample & $\begin{array}{c}\text { Jenkins and } \\
\text { Schreiner FOM }\end{array}$ & $\begin{array}{c}\text { FWHM of }(422) \\
\text { peak } 2 \theta\left(^{\circ}\right)\end{array}$ & $\begin{array}{l}\text { Observed peak } \\
\text { scatter }^{\mathrm{a}} 2 \theta\left(^{\circ}\right)\end{array}$ & $\begin{array}{c}\text { Smith and } \\
\text { Snyder FOM }\end{array}$ \\
\hline $\mathrm{UO}_{2}(\mathrm{~A})$ & 60 & 0.109 & $<0.007$ & 493 \\
\hline $\mathrm{UO}_{2}(\mathrm{~B})$ & 65 & 0.105 & $<0.005$ & 498 \\
\hline $\mathrm{UO}_{2}(\mathrm{C})$ & 48 & 0.146 & $<0.007$ & 324 \\
\hline
\end{tabular}

${ }^{\mathrm{a}}$ Value taken as the maximum difference between observed and theoretical peak positions. 


\section{Discussion}

\subsection{Sample preparation}

It is well known that freshly reduced fine $\mathrm{UO}_{2}$ powder is unstable in air at room temperature, i.e. it will rapidly absorb oxygen $[11-13,37]$. To minimize the uptake of oxygen we choose to produce sintered pellets with high densities ( $>97 \%$ T.D.). Any oxidation is then confined to the very surface of the sample (less than $5 \mathrm{~nm}$ ) and will not disturb the XRD analysis which has a substantially larger information depth, varying between $0.6 \mu \mathrm{m}$ for low-angle to $3.5 \mu \mathrm{m}$ for high-angle reflections [1]. This behavior is further confirmed by the fact that XRD patterns show no change after several weeks of exposure to the ambient atmosphere.

Two slightly different sintering atmospheres were applied: samples B and C underwent the most reducing condition $\left(-540 \mathrm{~kJ} \mathrm{~mol}^{-1}\right.$ at $\left.1680{ }^{\circ} \mathrm{C}\right)$, while a slightly less reducing condition $\left(-420 \mathrm{~kJ} \mathrm{~mol}^{-1}\right.$ at $\left.1680{ }^{\circ} \mathrm{C}\right)$ was applied for sample A. Using the equations of Lindemer and Besmann equilibrium values for different levels of hypo- and hyperstoichiometry of $\mathrm{UO}_{2 \pm x}$ as a function of temperature can be calculated (see Figure 3) [38]. The measured equilibrium lines of the applied gas mixtures $\left(\mathrm{H}_{2}, \mathrm{O}_{2}\right.$ and $\left.\mathrm{H}_{2} \mathrm{O}\right)$ for the two conditions are also presented in the same figure.

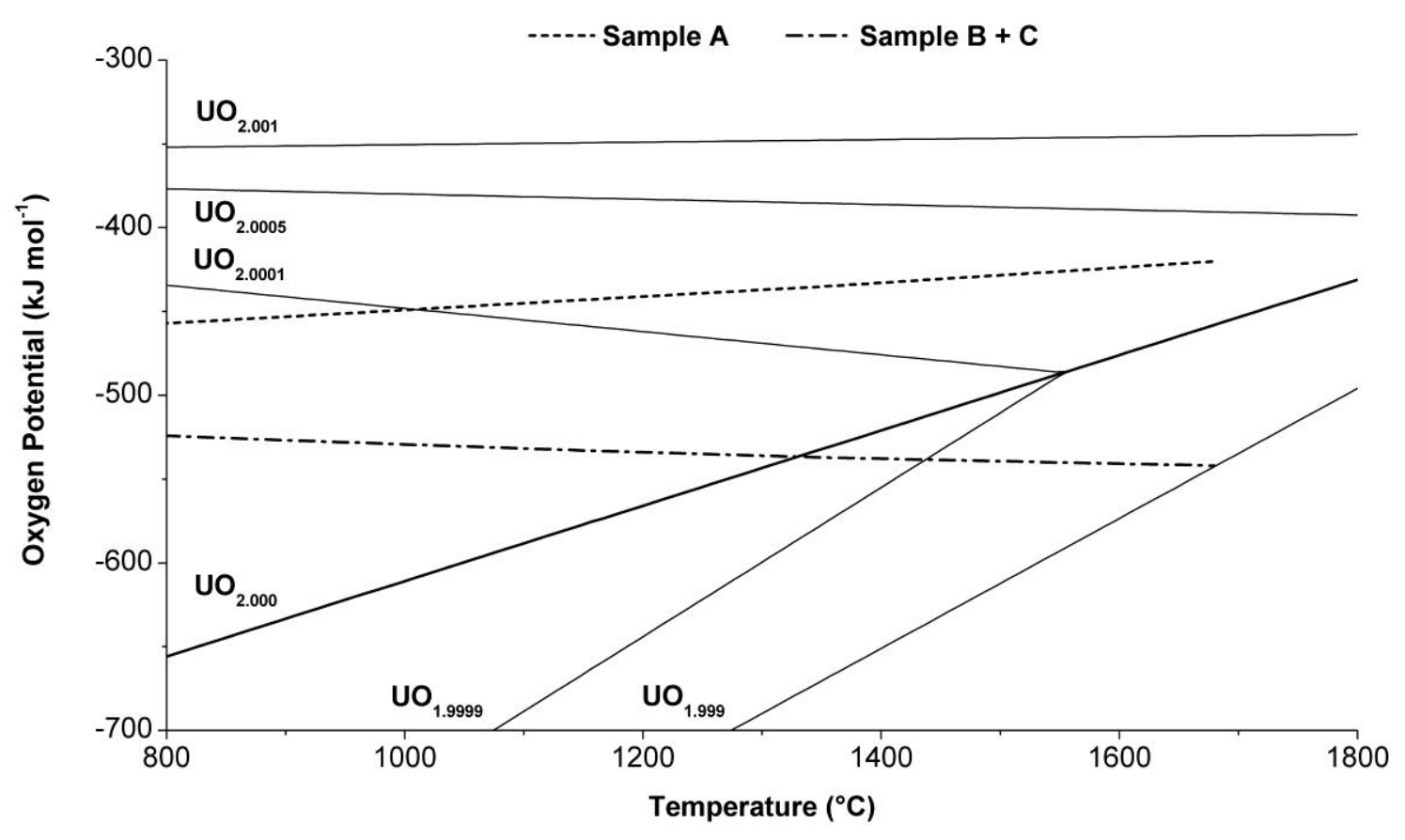

Figure 3. Ellingham diagram showing the oxygen potential equilibrium values of $\mathrm{UO}_{2 \pm x}$ according to the equations presented by Lindemer and Besmann [38]. The temperature dependent value of the oxygen potential according to the applied gas mixtures is shown by the dashed lines.

The most reducing condition (applied for samples B and C) is expected to yield a slight hypostoichiometry at sintering temperature, whereas the less reducing condition (sample A) is expected to yield a slight hyperstoichiometry. During cooldown, both atmospheres enter a 
domain of very slight hyperstoichiometry $(2.0000<\mathrm{O} / \mathrm{U}<2.0001)$. Sample A is thus always kept in slightly hyperstoichiometric conditions while samples $\mathrm{B}$ and $\mathrm{C}$ are expected to have gone from slightly hypo- to slightly hyperstoichiometry during cooldown.

\subsection{Stoichiometry measurement}

Given the sintering and cooling conditions and knowing that below $1200{ }^{\circ} \mathrm{C}$ there is no measurable hypostoichiometric $\mathrm{UO}_{2-\mathrm{x}}$ range $[2,3,17,39]$, the thermogravimetric results of Table 5 indicate that all samples are fully stoichiometric within the experimental uncertainty margin. It would indeed be highly improbable that sample A, which was kept in slight hyperstoichiometry during the complete sintering and cooldown process would be hypostoichiometric while the two other samples which were sintered at more reducing conditions actually have more elevated $\mathrm{O} / \mathrm{U}$ values. In fact, the uncertainty on exact stoichiometry may be considered to be single sided towards hyperstoichiometry.

By far, the largest contribution to the propagated error on stoichiometry originates from the uncertainty on the impurity content $(0.001$ for batch 1 and 0.0005 for batch 2 , see the first two rows in Table $6, \S 3.2$ ). It should be mentioned that if the impurity content would be entirely ignored (the terms $I_{O}$ and $C_{\mathrm{nq}}$ in Eq. (2) and the term $I$ in Eq. (3)) the O/U ratio would be underestimated by 0.002 . All other factors combined contribute to an uncertainty of \pm 0.0004 on the $\mathrm{O} / \mathrm{U}$ ratio. The propagated error is \pm 0.001 for batch 1 and \pm 0.0006 for batch 2 .

The used method for stoichiometry analysis is based on but not identical to the ASTM C1453-00 standard procedure. The latter measured a precision of \pm 0.002 on $\mathrm{O} / \mathrm{U}$ value, i.e. interlab tests on a series of reference samples gave a standard deviation of $\pm 0.002(1 \sigma)$. The uranium content in these reference samples was separately measured using two different techniques and had a relative uncertainty of $0.06 \%$, or \pm 0.01 on $\mathrm{O} / \mathrm{U}$. In this study, the propagated error on a single sample measurement is slightly smaller compared to the ASTM precision because in situ TGA measurements were used to define the stoichiometry. The listed $\mathrm{O} / \mathrm{U}$ values are corrected for non-quantifiable impurities, according to the ASTM standard procedure.

\subsection{Lattice parameter analysis}

In Table 7 (§3.3), the results of the lattice parameter analysis of three different samples were given and for each sample two measurements were performed, yielding a total of six measurements. After temperature correction to $20^{\circ} \mathrm{C}$, the $95 \%$ confidence interval of the individual observations overlap, and we consider the complete data set to be representative for 
the lattice parameter determination of $\mathrm{UO}_{2}$. The uncertainty on the average lattice parameter has several components: the dataset due to impurity content in solid solution, sintering conditions and sample degradation; the uncertainty of the individual refinements; temperature variation; and instrument bias. The contribution of the different sources of uncertainty are given in Table 9.

The population variance $\left(\sigma_{p o p}^{2}\right)$ estimates stochastic variations due to impurity effects, sample preparation and sample degradation. Numerous compounds are able to form a solid solution with $\mathrm{UO}_{2}$, thus influencing the lattice parameter of the unit cell [27,28,40-45]. Experimental data, however, is not yet available for every system. The chemical analysis of Table 3 was used as a basis for the estimation of the impact of the impurity content on the lattice contraction or expansion. With the given concentrations, the effect on the lattice parameter is two orders of magnitude less than the uncertainty on the lattice parameter and is also part of the variance of the individual measurements (sample $\mathrm{C}$ versus samples $\mathrm{A}$ and $\mathrm{B}$ ). Also the difference in sintering conditions (sample A versus samples B and C) is understood to be part of the population variance. Upon exposure of $\mathrm{UO}_{2}$ to the ambient atmosphere, its oxidation is expected to occur. By using densely sintered samples, this is expected to be sufficiently slow. By repeating measurements, possible degradation is part of the variation between the individual measurements (first versus second measurement of all samples).

The refinement uncertainty was better than $0.003 \mathrm{pm}$ for all analyses (see also Table 7), and in the summary of Table 9, the maximum uncertainty was taken to calculate the refinement variance $\left(\sigma_{a_{T}}^{2}\right)$.

The effect of sample temperature should not be underestimated. The variation on the lattice parameter value is $5 \times 10^{-3} \mathrm{pm}^{\circ} \mathrm{C}^{-1}$ [31]. For this reason, all samples were always thermally stabilized in the XRD apparatus overnight. The average value of the temperature inside the apparatus directly before and after the measurement was used to recalculate the lattice parameter value at $20^{\circ} \mathrm{C}$ (see also Table 7). The variance due to temperature uncertainty $\left(\sigma_{\Delta a}^{2}\right)$ is identical for all samples. The instrument bias was discussed earlier (see $\S 2.3$ ) and it appears that the variance due to instrument bias $\left(\sigma_{\text {instr }}^{2}\right)$ has the largest contribution in the total variance (Table 9).

Table 9. $\mathrm{UO}_{2}$ lattice parameter derived from the results listed in Table 7, total uncertainty and individual variances taken into account to derive the uncertainty on the lattice parameter value.

\begin{tabular}{ccccccc}
\hline $\begin{array}{c}\left\langle a>_{20}{ }^{\circ} \mathbf{C}\right. \\
(\mathbf{p m})\end{array}$ & $\begin{array}{c}\boldsymbol{\sigma}_{\text {total }} \\
(\mathbf{p m})\end{array}$ & $\begin{array}{c}\boldsymbol{\sigma}_{\text {pop }}^{2} \\
\left(\mathbf{p m}^{2}\right)\end{array}$ & $\begin{array}{c}\boldsymbol{\sigma}_{\boldsymbol{a}_{\boldsymbol{T}}}^{2} \\
\left(\mathbf{p m}^{2}\right)\end{array}$ & $\begin{array}{c}\boldsymbol{\sigma}_{\Delta \boldsymbol{a}}^{2} \\
\left(\mathbf{p m}^{2}\right)\end{array}$ & $\begin{array}{c}\boldsymbol{\sigma}_{\text {instr }}^{2} \\
\left(\mathbf{p m}^{2}\right)\end{array}$ & $\begin{array}{c}\boldsymbol{\sigma}_{\text {total }}^{2} \\
\left(\mathbf{p m}^{2}\right)\end{array}$ \\
\hline $\mathbf{5 4 7 . 1 2 7}$ & $\mathbf{0 . 0 0 8}$ & $2.0 \times 10^{-5}$ & $9.0 \times 10^{-6}$ & $4.0 \times 10^{-6}$ & $2.5 \times 10^{-5}$ & $5.8 \times 10^{-5}$ \\
\hline
\end{tabular}


In the early days of crystallography, X-ray wavelengths were defined in terms of the lattice parameter of calcite [46]. The relative unit known as $\mathrm{k} X$ was used. Values expressed in $\mathrm{k} X$ units could later be recalculated to $\AA$ units using a correction factor based on experimental data at that time. Throughout the years, this correction factor was adjusted due to advances in crystallography. In the early $1950 \mathrm{~s}$ the $\mathrm{CuK}_{\alpha 1}$ wavelength was defined as $1.53740 \mathrm{kX}$.

Recalculation using the factor 1.00202 yielded the absolute value of $1.54051 \AA$, as used by Grønvold and Lynds et al. [9,20]. In the 1960s, the correction factor was adjusted to 1.002056 and another relative wavelength unit was proposed by Bearden [47]. Alekseyev et al. utilized a value for $\mathrm{CuK}_{\alpha 1}$ of $1.54056 \AA$ [24]. The current value of the correction factor is 1.002077 , or a $\mathrm{CuK}_{\alpha 1}$ value of $1.540593 \AA$ [48]. The most accurate measurement of the absolute wavelength of $\mathrm{CuK}_{\alpha 1}$ was performed by Härtwig et al. in 1991 [33]. Their value of 1.5405929 $\AA$ is the currently accepted value $[49,50]$.

Much of the literature on the $\mathrm{UO}_{2}$ lattice parameter lacks information about the actual source wavelength used, i.e. the authors either mention the combined $K_{\alpha 1,2}$ value or they do not specify any value at all. When the source $\mathrm{K}_{\alpha 1}$ value is specified, however, one can recalculate the originally derived lattice parameter simply by multiplying with the ratio of current to old $\mathrm{K}_{\alpha 1}$ value. Of the values cited in table 1, only three can be recalculated: the value of Grønvold, that of Lynds et al. and that of Alekseyev et al. [9,20,24]. A recalculation using the currently accepted value of $1.5405929 \AA\left(\mathrm{CuK}_{\alpha 1}\right)$ results in a significant increase of their lattice parameter determinations (Table 10). Figure 4 presents in a graphical way the data of Table 10. It shows that the lattice parameter value determined in this work lies within the uncertainty range of the values reported by Grønvold and Lynds et al., but is not in agreement with the values reported by Alekseyev et al. and Cardinaels et al. [9,20,24,27].

Table 10. Recalculated lattice parameter values.

\begin{tabular}{lllll}
\hline $\begin{array}{l}\text { Reported } \\
\text { value }(\mathbf{p m})\end{array}$ & $\begin{array}{l}\text { Recalculated } \\
\text { value }(\mathbf{p m})^{\mathbf{a}}\end{array}$ & $\begin{array}{l}\text { Corrected to } \\
\mathbf{U O} \mathbf{2 . 0 0 0}^{\mathbf{b}} \mathbf{( \mathbf { p m } )}\end{array}$ & $\begin{array}{l}\text { Uncertainty } \\
(\mathbf{p m})\end{array}$ & Reference \\
\hline 546.96 & 546.97 & & \pm 0.04 & Alekseyev et al. [24] \\
547.03 & 547.06 & 547.07 & \pm 0.05 & Lynds et al. [20] \\
547.04 & 547.07 & & \pm 0.08 & Grønvold [9] \\
\hline
\end{tabular}

${ }^{\mathrm{a}}$ Recalculated using $\mathrm{CuK}_{\alpha 1}=1.5405929 \AA$.

${ }^{\mathrm{b}}$ Corrected to stoichiometry using the relation of Lynds et al. [20].

The $\mathrm{UO}_{2}$ lattice parameter derived in the current study $a=547.127 \pm 0.008$ (Table 9) is higher than many earlier reported values (Table 1), even when taking into account the correction for $\mathrm{CuK}_{\alpha 1}$ wavelength (Table 10). As a result, the theoretical density of $\mathrm{UO}_{2}$ calculated with the original lattice parameter value of Grønvold at $20{ }^{\circ} \mathrm{C}\left(10.9562 \pm 0.0048 \mathrm{~g} \mathrm{~cm}^{-3}\right)$ decreases slightly to $10.9510 \pm 0.0005 \mathrm{~g} \mathrm{~cm}^{-3}$ (both calculated for $\mathrm{M}_{\text {Unat }}=238.02891 \mathrm{~g} \mathrm{~mol}^{-1}$ and 
$\left.\mathrm{M}_{\mathrm{O}}=15.99940 \mathrm{~g} \mathrm{~mol}^{-1}\right)$. The uncertainty on the theoretical density is dominated by the uncertainty on the lattice parameter. When working with other enrichments, one must obviously take the effective mass of the actual uranium vector. The theoretical density of our samples (depleted uranium, see $\$ 3.1$ ) is calculated as $10.9515 \mathrm{~g} \mathrm{~cm}^{-3}$.

A main cause for the increased value of the lattice parameter is attributed to the avoidance of hyperstoichiometry. Ambient oxidation of $\mathrm{UO}_{2}$ powder may easily induce deviation from stoichiometry well in excess of 0.001 . In the present study, the use of densely sintered $\mathrm{UO}_{2}$ was adopted in order to prevent oxidation, while many of the earlier reported results stem from powder samples for which slight oxidation can not be ruled out.

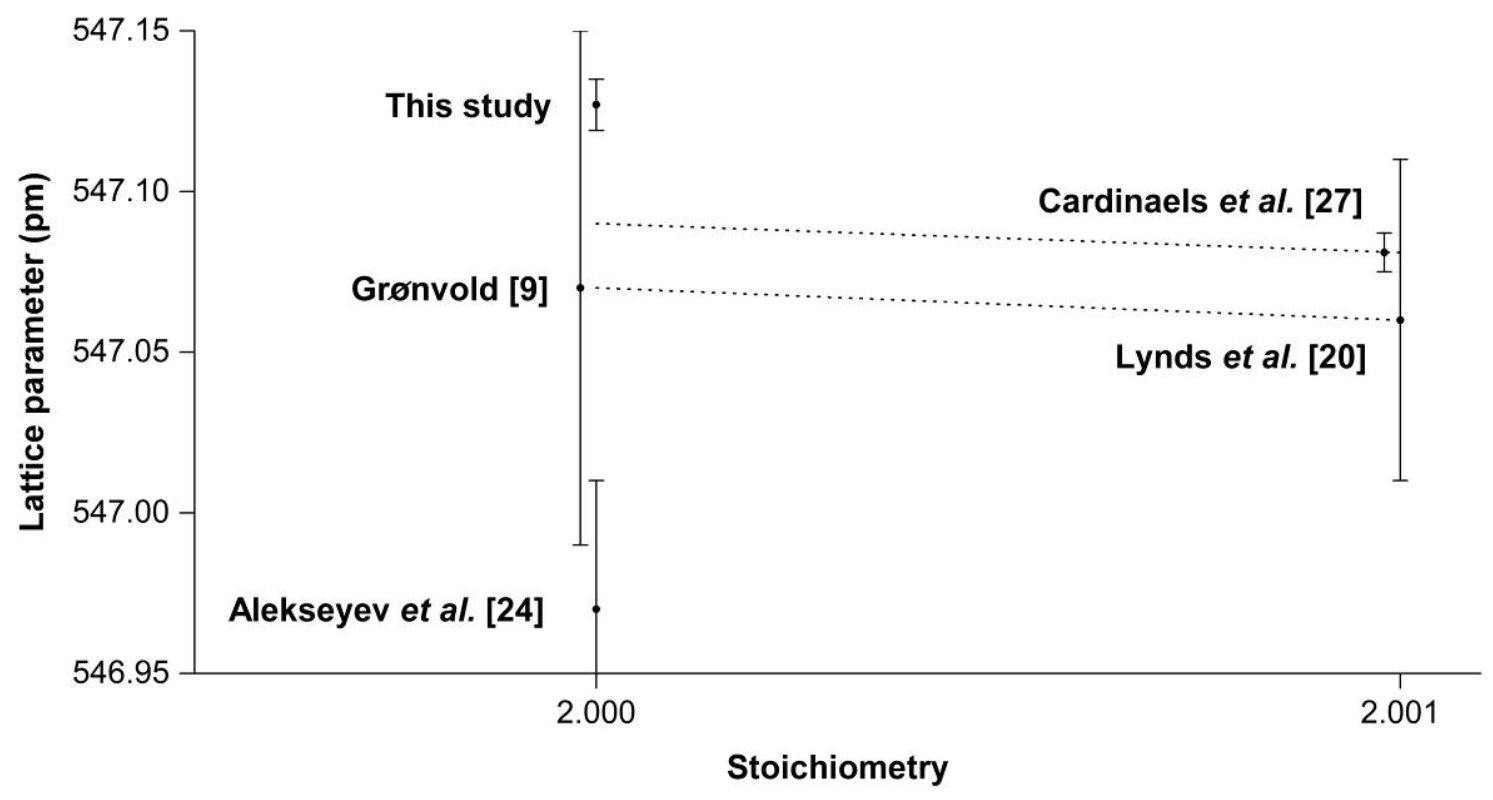

Figure 4. Presentation of the recalculated lattice parameter values of $\mathrm{UO}_{2}$. Additionally, the data of Cardinaels et al. is added [27]. For clarification, some of the data points are shifted slightly left of their original position. The dashed lines present the effect of correcting for hyperstoichiometry on lattice parameter value.

Material purity affects both stoichiometry and lattice parameter. As mentioned before, not correcting for the presence of impurities may result in an underestimation of up to 0.002 on stoichiometry, leading to a false interpretation of the measured lattice parameter. Few, if any, of the researchers cited in Table 1 performed a detailed impurity assessment. The use of lubricants or binders which contain a metallic compound should be avoided during pelletizing. The sample discussed by Cardinaels et al. was prepared with zinc stearate as a lubricant [27]. Although this compound is expected to evaporate during calcination, it is not unlikely that some $\mathrm{Zn}$ remains in the body and forms a solid solution with $\mathrm{UO}_{2}$, thus influencing the lattice parameter. 


\section{Conclusion}

In this paper, the lattice parameter of stoichiometric $\mathrm{UO}_{2}$ measured by X-ray diffraction on sintered pellets is reported. Furthermore, a discussion is given of the experimental difficulties encountered when preparing and measuring representative samples. The parameters influencing the accuracy of the lattice parameter measurement are carefully analyzed and evaluated.

XRD analysis performed over the course of two weeks gave consistent values for the lattice parameter of $\mathrm{UO}_{2}$. No significant difference in both stoichiometry and measured lattice parameter was found between samples sintered at very reducing $\left(-540 \mathrm{~kJ} \mathrm{~mol}^{-1}\right)$ or moderately reducing $\left(-420 \mathrm{~kJ} \mathrm{~mol}^{-1}\right)$ atmospheres. Also the effect of feed powder with slightly different impurity content was not measurable.

The stoichiometry of the samples could be accurately measured using gravimetric methods based on the ASTM C1453-00 standard procedure for measuring the uranium and oxygen-touranium atomic ratio by the ignition impurity correction method. The prepared samples are stoichiometric within the error of the measurement.

The lattice parameter of $\mathrm{UO}_{2.000} \pm 0.001$ is evaluated as $547.127 \pm 0.008 \mathrm{pm}$ at a temperature of $20{ }^{\circ} \mathrm{C}$, or $547.154 \pm 0.008 \mathrm{pm}$ at $25^{\circ} \mathrm{C}$. The significance of this re-evaluated value should not be underestimated. It is substantially higher than the generally accepted value of $547.04 \pm 0.08 \mathrm{pm}$ from Grønvold [9] and it results in a different theoretical density for $\mathrm{UO}_{2}$ $\left(10.9510 \pm 0.0005 \mathrm{~g} \mathrm{~cm}^{-3}\right.$ at $20{ }^{\circ} \mathrm{C}$ and $\left.\mathrm{M}_{\mathrm{UO} 2}=270.0277 \mathrm{~g} \mathrm{~mol}^{-1}\right)$, which is a key value in engineering context. Lattice contraction and lattice expansion studies are often performed to better understand the response of the $\mathrm{UO}_{2}$ lattice to irradiation effects, to understand the effect of doping or the effect of oxidation. Research results are often expressed relative to the value of the undisturbed $\mathrm{UO}_{2}$ system. Also for theoretical studies, structure data are often used either as input to develop parameterized interatomic potentials or to validate ab-initio calculations.

Older data on the lattice parameter of $\mathrm{UO}_{2}$ were critically evaluated and suggestions were made to correct some of these values. The generally accepted value of $547.04 \pm 0.08 \mathrm{pm}$ from Grønvold should be recalculated to $547.07 \pm 0.08 \mathrm{pm}$ as it was originally derived using a now outdated value of the $\mathrm{CuK}_{\alpha 1}$ wavelength [9].

\section{Acknowledgements}

G. L. thanks SCK•CEN for the financial support of this study. Also, the authors are indebted to Angela Baena for assisting in sample preparatory work, and Dr. Andrew Dobney for providing ICPMS and TIMS analysis. 


\section{References}

[1] R.J. McEachern, P. Taylor, J. Nucl. Mater., 254 (1998) 87.

[2] C. Guéneau, M. Baichi, D. Labroche, C. Chatillon, B. Sundman, J. Nucl. Mater., 304 (2002) 161.

[3] P.Y. Chevalier, E. Fischer, B. Cheynet, J. Nucl. Mater., 303 (2002) 1.

[4] V.A. Kurepin, J. Nucl. Mater., 303 (2002) 65.

[5] D. Labroche, O. Dugne, C. Chatillon, J. Nucl. Mater., 312 (2003) 21.

[6] D. Labroche, O. Dugne, C. Chatillon, J. Nucl. Mater., 312 (2003) 50.

[7] M. Baichi, C. Chatillon, G. Ducros, K. Froment, J. Nucl. Mater., 349 (2006) 57.

[8] M. Baichi, C. Chatillon, G. Ducros, K. Froment, J. Nucl. Mater., 349 (2006) 17.

[9] F. Grønvold, J. Inorg. Nucl. Chem., 1 (1955) 357.

[10] IAEA, "Thermophysical properties database of materials for light water reactors and heavy water reactors", IAEA, Vienna, 2006.

[11] M.J. Bannister, J. Nucl. Mater., 26 (1968) 174.

[12] L.E.J. Roberts, J. Chem. Soc., (1954) 3332.

[13] J.S. Anderson, L.E.J. Roberts, E.A. Harper, J. Chem. Soc., (1955) 3946.

[14] P.E. Blackburn, J. Weissbart, E.A. Gulbranson, J. Phys. Chem., 62 (1958) 902.

[15] C. Keller, "Comprehensive Inorganic Chemistry", Pergamon Press, Oxford, 1975.

[16] B.T.M. Willis, P. Brit. Ceramic Soc., 1 (1964) 9.

[17] I. Grenthe, J. Drozdzynski, T. Fujino, E.C. Buck, T.E. Albrecht-Schmitt, S.F. Wolf, "The chemistry of the Actinide and Transactinide elements", 3 ed., Springer, Dordrecht, 2006.

[18] B.T.M. Willis, Acta Crystallogr. A, 34 (1978) 88.

[19] P. Perio, Bull. Soc. Chim. Fr., (1953) 256.

[20] L. Lynds, A.W. Young, S.J. Mohl, G.G. Libowitz, "X-Ray and Density Study of Nonstoichiometry in Uranium Oxides", in: Nonstoichiometric Compounds, American Chemical Society, 1963, pp. 58-65.

[21] V.V. Rachev, V.S. Smurova, L.M. Kovba, E.A. Ippolitova, Zh. Neorg. Khim., 10 (1965) 2796.

[22] B. Belbeoch, J.C. Boivineau, P. Perio, J. Phys. Chem. Solids, 28 (1967) 1267.

[23] B. Touzelin, M. Dode, Rev. Int. Hautes Temp. Refract., 6 (1969) 267.

[24] V.A. Alekseyev, L.A. Anan'yeva, R.P. Rafal'skiy, Int. Geol. Rev., 23 (1981) 1229.

[25] K. Teske, H. Ullmann, D. Rettig, J. Nucl. Mater., 116 (1983) 260.

[26] Jmol: an open-source Java viewer for chemical structures in 3D. http://www.jmol.org/,

[27] T. Cardinaels, K. Govers, B. Vos, S. Van den Berghe, M. Verwerft, L. de Tollenaere, G.

Maier, C. Delafoy, J. Nucl. Mater., 424 (2012) 252.

[28] T. Cardinaels, J. Hertog, B. Vos, L.d. Tollenaere, C. Delafoy, M. Verwerft, J. Nucl. Mater., 424 (2012) 289.

[29] M.T. Hutchings, J. Chem. Soc. Farad. T. 2, 83 (1987) 1083. 
[30] H. Hering, P. Perio, Bull. Soc. Chim. Fr., 76 (1952) 351.

[31] J.K. Fink, J. Nucl. Mater., 279 (2000) 1.

[32] P.J. Mohr, B.N. Taylor, Rev. Mod. Phys., 77 (2005) 1.

[33] J. Härtwig, G. Hölzer, E. Förster, K. Goetz, K. Wokulska, J. Wolf, Phys. Status Solidi A, 143 (1994) 23.

[34] R. Jenkins, W.N. Schreiner, Powder Diffr., 4 (1989) 74.

[35] G.S. Smith, R.L. Snyder, J. Appl. Crystallogr., 12 (1979) 60.

[36] R. Jenkins, R.L. Snyder, "Reduction of Data from Automated Powder Diffractometers",

in: J.D. Winefordner (Ed.) Introduction to X-ray Powder Diffractometry, John Wiley \& Sons, Inc., 1996, pp. 287-317.

[37] H.R. Hoekstra, A. Santoro, S. Siegel, J. Inorg. Nucl. Chem., 18 (1961) 166.

[38] T.B. Lindemer, T.M. Besmann, J. Nucl. Mater., 130 (1985) 473.

[39] M.H. Rand, R.J. Ackermann, F. Gronvold, F.L. Oetting, A. Pattoret, Rev. Int. Hautes. Temp., 15 (1978) 355.

[40] H. Kleykamp, J. Nucl. Mater., 206 (1993) 82.

[41] H. Kleykamp, J. Nucl. Mater., 131 (1985) 221.

[42] R. Behera, C. Deo, H. Xu, J. Nucl. Mater., 433 (2013) 504.

[43] S.C. Middleburgh, D.C. Parfitt, R.W. Grimes, B. Dorado, M. Bertolus, P.R. Blair, L. Hallstadius, K. Backman, J. Nucl. Mater., 420 (2012) 258.

[44] J.W. McMurray, D. Shin, B.W. Slone, T.M. Besmann, J. Nucl. Mater., 443 (2013) 588.

[45] S.C. Middleburgh, R.W. Grimes, K.H. Desai, P.R. Blair, L. Hallstadius, K. Backman, P. Van Uffelen, J. Nucl. Mater., 427 (2012) 359.

[46] R. Jenkins, R.L. Snyder, "Characteristics of X-Radiation", in: J.D. Winefordner (Ed.) Introduction to X-ray Powder Diffractometry, John Wiley \& Sons, Inc., 1996, pp. 1-22.

[47] J.A. Bearden, Rev. Mod. Phys., 39 (1967) 78.

[48] P.J. Mohr, B.N. Taylor, D.B. Newell, Rev. Mod. Phys., 84 (2012) 1527.

[49] G. Hölzer, M. Fritsch, M. Deutsch, J. Härtwig, E. Förster, Phys. Rev. A: At. Mol. Opt. Phys., 56 (1997) 4554.

[50] M. Deutsch, E. Förster, G. Hölzer, J. Härtwig, K. Hämäläinen, C.C. Kao, S. Huotari, R. Diamant, J. Res. Natl. Inst. Stand. Technol., 109 (2004) 75. 